2-26-2011

Fuzzy logic: A "simple" solution for complexities in neurosciences?

Saniya Siraj Godil

Muhammad Shahzad Shamim

Ather Enam

Uvais Qidwai

Follow this and additional works at: https://ecommons.aku.edu/pakistan_fhs_mc_mc

Part of the Computational Neuroscience Commons, Neurology Commons, Neurosurgery Commons, and the Psychiatry Commons 


\title{
Fuzzy logic: A "simple" solution for complexities in neurosciences?
}

\author{
Saniya Siraj Godil, Muhammad Shahzad Shamim¹, Syed Ather Enam¹, Uvais Qidwai²
}

Faculty of Health Sciences, Medical College, Aga Khan University, Karachi, Pakistan, 'Section of Neurosurgery, Department of Surgery, Aga Khan University Hospital, Karachi, Pakistan, ${ }^{2}$ Department of Computer Science and Engineering, Qatar University, Qatar

E-mail: Saniya Siraj Godil- saniyasiraj@hotmail.com;*Muhammad Shahzad Shamim - shahzad.shamim@aku.edu; Syed Ather Enam- ather.enam@aku.edu; Uvais Qidwaiuqidwai@gmail.com

*Corresponding author

Received: I October 10

Accepted: 3 January II

Published: 26 February II

Surg Neurol Int 201 I, 2:24

This article is available from: http://www.surgicalneurologyint.com/content///2/24

Copyright: @ 20I I Godil SS. This is an open-access article distributed under the terms of the Creative Commons Attribution License, which permits unrestricted use, distribution, and

reproduction in any medium, provided the original author and source are credited.

This article may be cited as:

Godil SS, Shamim MS, Enam SA, Qidwai U. Fuzzy logic:A "simple" solution for complexities in neurosciences? Surg Neurol Int 2011;2:24

Available FREE in open access from: http://www.surgicalneurologyint.com/text.asp? 201 1/1/2/77177

\begin{abstract}
Background: Fuzzy logic is a multi-valued logic which is similar to human thinking and interpretation. It has the potential of combining human heuristics into computerassisted decision making, which is applicable to individual patients as it takes into account all the factors and complexities of individuals. Fuzzy logic has been applied in all disciplines of medicine in some form and recently its applicability in neurosciences has also gained momentum.
\end{abstract}

Methods: This review focuses on the use of this concept in various branches of neurosciences including basic neuroscience, neurology, neurosurgery, psychiatry and psychology.

Results: The applicability of fuzzy logic is not limited to research related to neuroanatomy, imaging nerve fibers and understanding neurophysiology, but it is also a sensitive and specific tool for interpretation of EEGs, EMGs and MRIs and an effective controller device in intensive care units. It has been used for risk stratification of stroke, diagnosis of different psychiatric illnesses and even planning neurosurgical procedures.

Conclusions: In the future, fuzzy logic has the potential of becoming the basis of all clinical decision making and our understanding of neurosciences.

Key Words: Fuzzy logic, neurosciences, neurology, neurosurgery, psychiatry

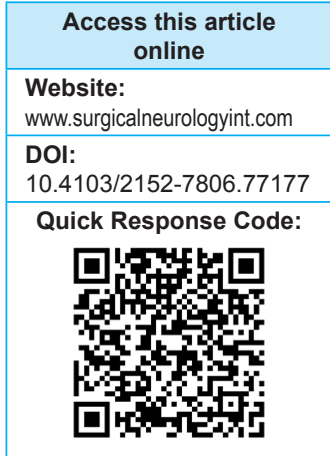

\section{INTRODUCTION}

Man is God's most complex creation. Clinical judgment for the diagnosis and management of mans' diseases is an art. It can neither be acquired from textbooks alone, nor can it be taught, but has to be developed slowly through years of observation and experience. This is because unlike other professions, which thrive on calculations based on yes/no or present/absent, very little is clearly black and white in clinical medicine. Most clinical scenarios present in shades of gray. Instead of "present or absent", patients' symptoms are described using terms like "never, rarely, sometimes, often, most of the times, always, etc". Moreover, each specific symptom may also be graded as 
"mild, moderate or severe". This is compounded by the fact that most symptoms are experienced and described differently by patients and many symptoms may overlap in the same patient. Each individual patient may also have a multitude of characteristics other than the disease, rendering it unique in itself. Medical problems, therefore, cannot be generalized and analyzed using Aristotelian or binary logic, and an analytical program is desperately required which could integrate this complex network of problems and devise individualized solutions. Fuzzy logic is the nearest response to the call. It has the potential of combining human heuristics into computer-assisted decision making. Imagine combining the experience of five university professors with all the current literature and developing a software that can calculate probabilities based on this, tailored specifically for each individual patient. Fuzzy logic can do all that.

The concept was first introduced by Lotfi Zadeh in 1965. ${ }^{[111]}$ He defined fuzzy logic as "a class of objects with a continuum of grades of membership". ${ }^{[11]}$ It accounts for all the complexities and variations in patients and results in a statistical analysis which is appropriate for an "individual", unlike evidence-based medicine, which is applicable to a group of patients. ${ }^{[4+]}$ It enables the scientific community to look into all shades of gray and determine the grade and severity of the disease. Fuzzy logic is a well-established concept in mathematics and engineering but its usefulness in medicine was not realized till the last decade. A recent review highlighted that the medical publications on fuzzy logic increased from 2 per year in 1991 to 175 per year in 2002..99] Till last year, a Medline search using the keyword "fuzzy logic" generated around 1600 publications, ${ }^{[95]}$ but a recent Medline search generated a total of 2448 articles, out of which more than 300 were published during last year. This reflects that the use and applicability of fuzzy logic is accelerating at a significant pace in medical and scientific community.

\section{WHAT IS FUZZY LOGIC?}

Fuzzy logic is a multi-valued logic which was introduced by Zadeh in order to deal with vague and indecisive ideas. $^{[111]}$ It has been described as an extension to the conventional Aristotelian and Boolean logic as it deals with "degrees of truth" rather than absolute values of "0 and 1" or "true/false". Fuzzy logic is not like a computer software which understands only binary functions or concrete values like 1.5, 2.8, etc; instead, it is similar to human thinking and interpretation and gives meaning to expressions like "often", "smaller" and "higher". Fuzzy logic takes into account that real world is complex and there are uncertainties; everything cannot have absolute values and follow a linear function.

Characteristics of Fuzzy Logic

There are a few basic principles of fuzzy logic which were laid down by Zadeh in 1992:[110]

- Exact reasoning is viewed as a limiting case of approximate reasoning.

- Everything is a matter of degree.

- Knowledge is interpreted as a collection of elastic, fuzzy constraints on a collection of variables.

- Inference is viewed as a process of propagation of elastic constraints.

- Any logical system can be "fuzzified".

Fuzzy Sets

A classical set of binary logic has "crisp" boundaries whereas fuzzy sets have fuzzy or imprecise boundaries. A fuzzy set consists of linguistic variables where values are words and not numerical. ${ }^{[110-111]}$ For example, intracranial pressure (ICP) can be defined as low, normal or high. Thus, ICP is a linguistic variable where the values have fuzzy margins and can overlap each other [Figure 1]. The transition from one value to another is gradual and each value is given a membership function which represents the degree to which it belongs to that value. A fuzzy set can be represented by the following equation: ${ }^{[5]}$

$A=\left\{\left(x, \mu_{A}(x)\right) \mid x \in X\right\}$

where $A$ is a fuzzy set in $X$ and $\mu_{A}(x)$ is the membership function, which can have any value between 0 and 1 inclusive.

Membership functions overlap each other as evident in Figure 1. Thus, a value for ICP can be both low and normal to a certain degree. Membership functions are not equivalent to probabilities. A membership value of low ICP does not signify that there is a certain probability of having low ICP or not; instead it is the degree to which it is a low ICP.

Fuzzy Rules

Fuzzy rule is based on "if...then" rule and connects the different input and output fuzzy variables. ${ }^{[110]}$ It can be expressed as:

if is $x A$ then $y$ is $B$

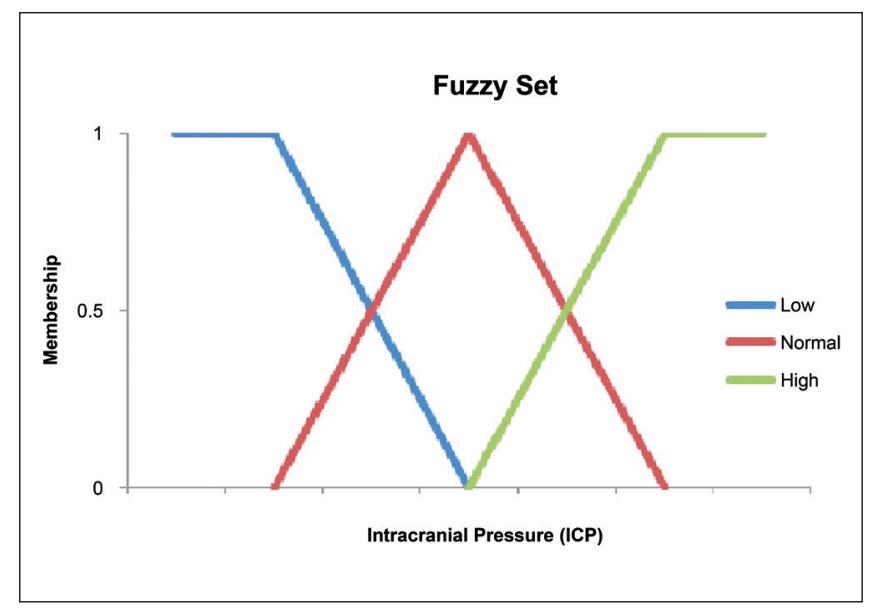

Figure I: Fuzzy sets: low, medium and high 
where $A$ is the antecedent and $B$ is the consequent. Fuzzy rules are similar to common sense rules as they resemble human thinking and are based on human experience. For example, in order to control ICP in a patient with traumatic brain injury, sedation is often required but needs to be carefully monitored. A simple rule can be, "If the ICP is high, increase propofol infusion", or "If the ICP is low, stop propofol infusion". These rules are based on collective experience of specialists in the field as well as available literature. Thus, as more fuzzy rules and sets are obtained from various sources, uncertainties are potentially reduced.

\section{Fuzzy Reasoning}

Fuzzy reasoning is also called approximate reasoning and is the process of drawing conclusions from fuzzy sets and fuzzy rules.

\section{Fuzzy Inference System}

Fuzzy inference system (FIS) is a framework which is based on fuzzy sets, fuzzy rules and fuzzy reasoning. ${ }^{[78]}$ It has four main components including fuzzifier, rule base, inference engine and defuzzifier ${ }^{[106]}$ [Figure 2]. The fuzzifier creates fuzzy sets from "crisp" values like a fuzzy set for ICP will be divided into "low, normal and high" and a fuzzy set for propofol infusion will be divided into "stop, decrease and increase". Next, the fuzzy rules are formed based on these two input fuzzy sets: "If the ICP is low, stop propofol infusion", "If the ICP is normal decrease propofol infusion" and "If the ICP is high, increase propofol infusion". The inference engine applies all the fuzzy rules on the fuzzy sets to determine the resultant fuzzy output. If a "crisp" output value is required, the process of defuzzification converts the fuzzy output into a "crisp" output value by determining the center of mass of the combined, overlapping membership functions.

\section{EXAMPLES OF A FUZZY LOGIC NETWORK}

Microdiskectomy is a common surgical procedure

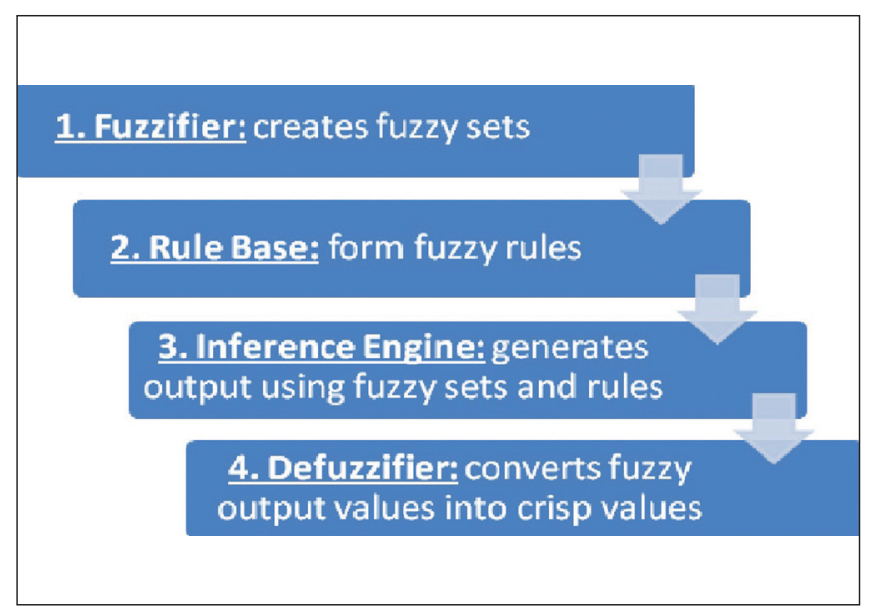

Figure 2: Components of fuzzy inference system performed for low back pain and radiculopathy due to disc herniation. It provides symptom relief in most patients. However, a few patients fail to improve after this surgical procedure and fuzzy logic based FIS was used by Shamim et al, to predict this group of patients with failed microdiskectomy. ${ }^{[95]}$

A retrospective review of 501 patients who underwent microdiskectomy was done. A total of 16 variables from a list of 54 variables were classified as risk factors for failed microdiskectomy by an expert in the field. These variables were taken as membership function and the degrees of membership were defined. A rule base of 11 fuzzy rules was formed and each rule formed a decision bar which together made up the total decision surface. The centroid of each decision surface formed the basis of FIS decision. The output variable defined the risk of failed microdiskectomy as "very low", "low" or "high" risk. The sensitivity and specificity of the FIS was calculated by comparing these results of FIS with the actual outcome of all patients at a six-month postoperative follow-up. The sensitivity and specificity of this FIS was found to be $88 \%$ and $86 \%$, respectively. ${ }^{[95]}$

Another example highlights the application of FIS in predicting trauma-related mortality. ${ }^{[109]}$ Retrospective data of 150 trauma patients was collected including GCS, systolic blood pressure and different trauma scores (Injury Severity Score [ISS], Revised Trauma Score [RTS], A Severity Characterization of Trauma [ASCOT] and Trauma and Injury Severity Score [TRISS]) at arrival, one hour after resuscitation and at the time of ICU admission. By using the different trauma scores, mortality prediction was calculated at the time of arrival, 1 hour after resuscitation and at the time of ICU admission. For fuzzy logic, the membership functions of GCS and systolic blood pressure (e.g. very low, low, normal, high) as well as change in GCS and systolic blood pressure at 1 hour and at the time of ICU admission (e.g. decrease, stationary, increase) were defined. Different fuzzy rule blocks were made using these membership functions. For example very low GCS and systolic blood pressure at arrival and a decrease in GCS and blood pressure after resuscitation predict very high mortality. The FIS designed integrated all these membership functions and fuzzy rules to predict mortality of these patients using Mamdani center-of-gravity algorithm. FIS (ROC: 0.9247) performed better than other conventional scoring systems (ROC: 0.9033).

One of the most important uses of fuzzy logic is in drug delivery devices. Special fuzzy logic controllers have been designed for use in anesthesia and intensive care units. One of the studies used auditory evoked potential as a measure of depth of anesthesia and the fuzzy controller administered a certain amount of drug based on it. ${ }^{[8]}$ Similarly neuromuscular blocking agents are administered 
during surgery by monitoring the response at ulnar nerve; if the response at ulnar nerve is greater, more neuromuscular blocker is administered by the fuzzy controller. ${ }^{[85]}$

All these examples clearly indicate that fuzzy logic networks and systems can easily solve various complex clinical problems.

\section{ADVANTAGES AND DISADVANTAGES OF FUZZY LOGIC}

Fuzzy logic is a solution to complex problems in all fields of life, including medicine, as it resembles human reasoning and decision making. It looks into all shades of gray and answers uncertainties and ambiguities created by human language where everything cannot be described in precise and discrete terms. Fuzzy systems help define disease extent and severity and answer questions related to individual patients taking into account their risk factors and co-morbidities.

On the other hand, it has a number of disadvantages too. It is tedious to develop fuzzy rules and membership functions and fuzzy outputs can be interpreted in a number of ways making analysis difficult. In addition, it requires lot of data and expertise to develop a fuzzy system. It does not give generalizable results and the program has to be run for each individual patient. Therefore, its clinical applicability and utilization is difficult without the availability of preprogrammed softwares for different pathologies and the basic training of clinicians to use these programs.

\section{FUZZY LOGIC IN MEDICINE}

The application on fuzzy logic in medicine gained momentum in last two decades ${ }^{[76,99]}$ when the usefulness of this technique was realized to correlate with the fuzzy nature of this field. In this era of technological advancements, most of the human workforce has been replaced by machines and robots and fuzzy logic is the means by which a system can be formulated, whereby machines can perform tasks by using rules similar to human reasoning and logic.

All the disciplines of medicine have used fuzzy logic in some way. The various applications include: assessing the effectiveness of drugs, ${ }^{[75]}$ early detection of diabetic retinopathy and neuropathy, ${ }^{[112]}$ treatment of tropical diseases ${ }^{[73]}$ and diagnosis of diabetes, cardiac, renal and liver diseases ${ }^{[3,51,54]}$ where it has shown an accuracy of $79.37 \%$ in diagnosing diabetes and $97.55 \%$ in diagnosing dermatological diseases. ${ }^{[52]}$ In pulmonary medicine it has been used for chronic obstructive pulmonary disease, evaluating pulmonary function tests, as well as for ventilator support of patients in intensive care unit
(ICU). ${ }^{[13,30,70,102]}$ In ICU setups, FIS has been shown to monitor patients, control blood pressure, provide adequate analgesia and anesthesia, assess ventilation requirements and even control ventilator settings, etc. ${ }^{[14,25,29]}$ FIS has also been shown to help in controlling tidal volume, maintaining end-tidal $\mathrm{PCO}_{2}$ and controlling administration of neuromuscular blockade during surgery, ${ }^{[28,60-61,71-72,90]}$ as well as maintenance of depth of anesthesia and optimum conditions for surgery. ${ }^{[40]}$ In oncology, detection of cancers, including lung, breast and prostate cancer, can be aided with fuzzy logic. ${ }^{[64,93-94]}$ It can also predict surgical outcomes and prognosis in malignancies ${ }^{[46,92]}$ and can be used to decide radiotherapy margins. ${ }^{[67]}$ It is also helpful in analyzing PET scan images for quantification of cancers. ${ }^{[16]}$

Fuzzy logic is not only applicable to clinical medicine, but it has been a useful statistical tool in basic sciences and bioinformatics as well. ${ }^{[99]}$ DNA sequencing, studying the complete genome and differences between polynucleotides and understanding various signaling pathways and cell signaling networks is possible by using fuzzy logic. $[6,24,38,66,82,100]$

\section{FUZZY LOGIC IN NEUROSCIENCES}

In comparison to applicability of fuzzy logic in medicine and basic sciences, the concept is still new in the field of neurosciences. This was clearly highlighted in the review published on fuzzy logic where the contribution to the literature on fuzzy logic was much less from neurosciences as compared to other disciplines of medicine ${ }^{[59]}$ However, the last decade has witnessed the acknowledgment of usefulness of fuzzy logic in various branches of neurosciences including basic neurosciences, neurology, neurosurgery, neuroradiology, psychiatry and psychology. ${ }^{[15,95,99]}$

\section{Basic Neurosciences}

Fuzzy model has been shown to be an effective tool for research related to neuroanatomy and has been used for imaging nerve fibers. ${ }^{[12,108]}$ Controller systems based on fuzzy logic are also capable of controlling electrical responses, like potential difference and current, of nerve fibers. ${ }^{[4]}$ Additionally, it has also been used in tracking eye movements and characterizing horizontal and vertical nystagmus ${ }^{[9]}$ and studying neural circuits in primary visual cortex. ${ }^{[36]}$ It can be utilized in understanding the sensorimotor behavior of individuals as well as other complex neurophysiological concepts and neuron circuitry. ${ }^{[80]}$

\section{Neurology}

Fuzzy logic has been used in the diagnosis, management and outcome prediction of common neurological diseases with considerable success. Stroke is a multifactorial disease and the causal relationship is complex. Jobe 
et $a l$, showed that all probabilistic-statistical methods are ineffective in explaining this complex relationship except fuzzy model, which is a good tool to understand the disease causality. ${ }^{[43]}$ Another study on stroke patients, comparing statistical versus fuzzy measures, also concluded that fuzzy measures are a better representation of the actual, individual patient as compared to other statistical measures which apply to a group of patients and not individuals. ${ }^{[35]}$ Fuzzy logic has been shown to be superior to evidence-based medicine in complex clinical scenarios ${ }^{[32-33]}$ and cases where individual factors of patients are important to consider, for example, administration of warfarin in stroke patients. ${ }^{[31,34]}$ Fuzzy clustering method has also been applied on stroke patients to analyze different biomechanical forces and devise an effective rehabilitation program according to their specific requirements. ${ }^{[2]}$

FIS has also been implicated in the study and interpretation of EEG. Aarabi et al, developed a FIS, which was highly sensitive (sensitivity: 98.7\%) in detecting seizures via intracranial EEG. ${ }^{[1]}$ It is a remarkable finding as the detection of seizures by FIS was comparable to the detection by experts. Fuzzy index can distinguish between EEG signals from normal individuals and those from epileptic patients ${ }^{[101]}$ and help in the diagnosis of epilepsy with a sensitivity of $84.9 \% .^{[18,22]}$ EEG analysis using FIS can also be used to determine the depth of anesthesia. ${ }^{[53]}$ Fuzzy system has also been shown to accurately identify different stages of sleep $84.6 \%$ of the times based on EEG findings. ${ }^{[42]}$

A fuzzy logic based biofeedback system through EMG has been found to significantly change the activation pattern of trapezius muscle during active and passive shoulder movements $(P$ value $<0.05){ }^{[88]}$ The feedback significantly changes the spatiotemporal activity of the trapezius muscle $(P$ value $<0.05)$. $^{[87]}$ In a study by Kocer et al, EMG signals from various patients were classified and analyzed with the help of neuro-fuzzy system. This system can help in the diagnosis of various neuromuscular diseases, including myopathies and neuropathies, based on EMG findings. ${ }^{[47]} \mathrm{A}$ technique introduced by Chauvet can be used to study the physiological properties of muscles without using invasive methods. ${ }^{[19]}$ By this technique, the EMG signals, classified using fuzzy logic, were decomposed into motor unit action potential trains and the error rate was found to be only $1.37 \%$ as 21 action potential trains were detected using this technique as compared to 29 detected by neurophysiologists. ${ }^{[19]}$

Fuzzy logic and application of different fuzzy rules can successfully predict and model human stance and gait which is controlled by the length of limb, its orientation and trunk attitude. ${ }^{[39]}$ Zhang et al, have also developed a motor system for functional electric stimulation locomotion which is controlled by neural network and fuzzy logic. ${ }^{[13]} \mathrm{A}$ simulation model consisted of 7 segments and 18 muscles and had a satisfactory performance. Thus, this system can be used for locomotion in paraplegic patients. Recently, programmed logic controllers have been developed which use EEG signals from motor cortex as control signals and can be fitted into devices like wheel chairs and electronic machines, which can be used by disabled people. ${ }^{[41]}$

\section{Neurosurgery}

The concept of fuzzy logic has been applied in neurosurgical ICUs for precise control of different parameters like ICP and blood pressure. Fuzzy logic based controllers are found effective at maintaining stable ICP via varying propofol infusion rates. ${ }^{[37,83-84,97]}$ Fuzzy logic can also be used to estimate ICP non-invasively by using different parameters like cerebral blood flow velocity and arterial blood pressure with the difference between the actual and estimated ICP being only $5.7 \mathrm{mmHg} .{ }^{[91]}$

A fuzzy Glasgow Coma Scale (GCS) has been introduced and was used in a study conducted on traumatic brain injury patients in India. ${ }^{[10]}$ The study showed that the non-specificity of classical and fuzzy GCS is comparable, as fuzzy GCS was able to effectively predict full cognitive recovery. Eye, visual and motor stimuli were all found to be significantly associated with cognitive recovery ${ }^{[10]}$ For general trauma, Kilic et al, have devised a FIS which has been shown to predict trauma-related mortality (ROC: 0.925) as well as conventional systems (ROC: 0.903). ${ }^{[109]}$ Outcome of surgeries can also be predicted with the help of fuzzy logic. It has been shown that FIS has a sensitivity of $88 \%$ and specificity of $86 \%$, with positive and negative predictive value of 0.36 and 0.98 , respectively, for predicting poor outcomes in patients undergoing lumbar disc surgery. ${ }^{[95]}$ Fuzzy logic has been used to develop a successful software for evaluating neurosurgical patients with brain tumors in clinic and estimate the tumor volume which will determine the treatment plan. ${ }^{[56]}$ The mean operating time for the software is just 16 minutes and operator variability is less than $1 \%$.

Samejima et al, developed a screening tool for unruptured aneurysm using fuzzy logic, based on the data from a retrospective study and opinions of experienced neurosurgeons and this tool was shown to detect 12 new cases of unruptured intracranial aneurysm. ${ }^{[89]}$ Recently, another tool has been developed to predict outcomes of patients with intracranial aneurysm. ${ }^{[57]}$ This study showed that the fuzzy logic based predictive tool was effective as the predicted outcomes correlated with the actual outcomes. The NASA smart probe project has used fuzzy logic in the development of probes for realtime identification of gray and white matter in brain and differentiation between normal tissue and tumor cells. $^{[11,86]}$ Surgery for deep brain stimulation can also be planned by combining data from MRI images and 
expert opinions with the help of fuzzy logic. ${ }^{[105]}$ This can result in targeting the exact anatomical area and increase the success of surgery. Hemm et al, showed that using fuzzy logic helps in better anatomical localization of structures and placement of electrodes for deep brain stimulation. ${ }^{[98]}$

Surgical planning for correcting spinal deformities is another area where fuzzy logic has been used effectively. An important decision for these surgeries is the level at which surgical correction is required. It is highly dependent on opinion of experienced surgeons, and using fuzzy logic, has now been integrated into a model to aid in surgical planning. ${ }^{[69]}$ Miller et al, have designed a modular surgical instrument based on FIS which has been shown to reduce operating time by almost $7 \%$ by efficiently managing the workflow and handling of surgical instruments. ${ }^{[63]}$ This instrument was designed for laparoscopic surgeries but can be applied to any form of surgeries and robotic systems.

Morphometric measurements and analyses of gray and white matter of spine can also be done using fuzzy logic in patients with spinal cord injury. ${ }^{[2]}$ Ellingson et al, found that cervical spinal cord is significantly affected during injury to caudal spinal cord, diffusion is reduced in both gray and white matter but atrophy in white matter tracts, measured using FIS, is higher as compared to gray matter. ${ }^{[26]}$

\section{NEURORADIOLOGY}

MRI is the most commonly used radiological investigation for diagnosis of brain tumors and stroke. A number of studies have been conducted to analyze MRI images using fuzzy models. ${ }^{[45,55,114]}$ Fuzzy logic has a higher sensitivity of detecting small lesions of stroke and emboli and also identifying normal structures. ${ }^{[48,96]}$ Fuzzy cluster can be used to accurately characterize gliomas into high grade and low grade $(P$ value $<0.001)$ and determine glioma volume before surgery. ${ }^{[27,65,77]}$ The diagnosis of grade of gliomas, based on interpretation of MRI scans using fuzzy logic, has been shown to have an accuracy of $86.4 \%$. $^{[107]}$ It is also able to detect brain tumor response to radiation therapy by measuring changes in volume after treatment. ${ }^{[103-104]}$ Additionally, it can differentiate tumor tissue from surrounding edema and hemorrhage. ${ }^{[77,79]}$ Apart from the tumor volume, fuzzy clustering can detect CSF and gray and white matter volume changes in children with hydrocephalus. ${ }^{[17]}$

Classification and segmentation of the cerebral hemispheres, cerebellum and deep structures of the brain can be performed by fuzzy systems using information from the anatomical atlas and MRI image characteristics. ${ }^{[7,20-21]}$ Fuzzy connectivity has been used for segmentation and identification of black spots in multiple sclerosis. ${ }^{[23]}$

Till date, there are no specific diagnostic criteria for diagnosis of cortical malformation which is a common neurological problem leading to epilepsy, mental retardation and developmental delay in children. A recent paper has used fuzzy logic to incorporate expert opinions and formulate a system for diagnosis of cortical malformation. ${ }^{[5]}$

Psychiatry and Psychology

A fuzzy logic based software has been designed to keep a track of psychiatric patients. It includes all the recent diagnostic criteria for different disorders and has complete details of the patients' histories and follow ups which help in the management of these patients as well as assisting in research. ${ }^{[49]}$ Diagnosis of sleep disorders is dependent on clinician's experience. Fuzzy logic has been shown to aid in the recognition and diagnosis of sleep disorders by analyzing data of opinions from experts. ${ }^{[7]}$

Qing et al, developed a fuzzy logic based functional MRI model for the evaluation of depression and its severity. ${ }^{[81]}$ The correlation value between this model and standard depression severity scale was 0.7886 , which signifies that it can be used to evaluate the severity of depression as well as to track the course of illness. Fuzzy logic is a sensitive technique, with an error rate of just $5.93 \%$, in assessing weight changes in schizophrenic patients on antipsychotic drugs. ${ }^{[50]}$ It is also used in auditory electrophysiological monitoring of patients with schizophrenia. ${ }^{[115]}$

Fuzzy systems have been successfully developed to monitor drug response in patients with drug dependence. The example of one such model is use of citalopram in alcohol drug dependence where high correlation $(r$ $=0.99, P$ value $<0.001)$ was seen between the actual and predicted response rate. ${ }^{[68]}$ Fuzzy logic has also been applied in study of psychology. It was used in the interpretation of whether perception of speech varies with using upright or inverted facial images or not. ${ }^{[62]}$ It has also been used to develop a model of emotions where the influence of different events and experiences on emotional process can be studied. ${ }^{[58]}$

\section{FUTURE DIRECTIONS}

The above discussion clearly highlights fuzzy logic as a sensitive and specific tool for various clinical problems. Although, a number of studies have been conducted on fuzzy logic, it is still largely underutilized in neurosciences. On one hand, where the concept has the potential of changing medical diagnosis and management completely, it remains to be seen how effectively it can be incorporated in routine clinical practice. If focused research is conducted, it is possible that in future neurophysiology labs will be reporting EMGs and EEGs with the help of fuzzy logic, ICUs will have 
fuzzy controllers for controlling blood pressure, ICP and ventilator settings, MRI scans will be analyzed by fuzzy logic softwares and neurosurgeries will be planned by FIS. However, change is always difficult to introduce. God's most complex creation remains a creature of habit.

\section{REFERENCES}

I. Aarabi A, Fazel-Rezai R, Aghakhani Y. Seizure detection in intracranial EEG using a fuzzy inference system. Conf Proc IEEE Eng Med Biol Soc 2009;2009:1860-3.

2. Aissaoui R, Desroches G. Stroke pattern classification during manual wheelchair propulsion in the elderly using fuzzy clustering. J Biomech 2008;41:2438-45.

3. Akinyokun CO, Obot OU, Uzoka FM, Andy JJ. A neuro-fuzzy decision support system for the diagnosis of heart failure. Stud Health Technol Inform 2010;156:231-44.

4. al-Holou N, Joo DS. Development of a fuzzy logic based system to monitor the electrical responses of nerve fiber. Biomed Sci Instrum 1997;33:376-8I.

5. Alayon S, Robertson R,Warfield SK, Ruiz-Alzola J.A fuzzy system for helping medical diagnosis of malformations of cortical development.J Biomed Inform 2007;40:22I-35.

6. Aldridge BB, Saez-Rodriguez J, Muhlich JL, Sorger PK, Lauffenburger DA. Fuzzy logic analysis of kinase pathway crosstalk in TNF/EGF/insulin-induced signaling. PLoS Comput Biol 2009;5:e 1000340.

7. Algorri ME, Flores-Mangas F. Classification of anatomical structures in MR brain images using fuzzy parameters. IEEE Trans Biomed Eng 2004;51: 1599-608.

8. Allen R, Smith D. Neuro-fuzzy closed-loop control of depth of anaesthesia. Artif Intell Med 200I;2I:185-9I.

9. Allum $\mathrm{JH}$, Honegger $F$,Troescher M. Principles underlying real-time nystagmus analysis of horizontal and vertical eye movements recorded with electro-, infra-red-, or video-oculographic techniques. JVestib Res 1998;8:449-63.

10. Amin AP, Kulkarni HR. Improvement in the information content of the Glasgow Coma Scale for the prediction of full cognitive recovery after head injury using fuzzy logic. Surgery 2000; 127:245-53.

II. Andrews RJ, Mah RW.The NASA Smart Probe Project for real-time multiple microsensor tissue recognition. Stereotact Funct Neurosurg 2003;80:I I 4-9.

12. Axer H, Jantzen J, Keyserlingk DG, Berks G. The application of fuzzy-based methods to central nerve fiber imaging. Artif Intell Med 2003;29:225-39.

13. Bates JH, Hatzakis GE, Olivenstein R. Fuzzy logic and mechanical ventilation. Respir Care Clin N Am 2001;7:363-77, vii.

14. Bates JH, Young MP. Applying fuzzy logic to medical decision making in the intensive care unit. Am J Respir Crit Care Med 2003;167:948-52.

15. Bay OF, Usakli AB. Survey of fuzzy logic applications in brain-related researches. J Med Syst 2003;27:215-23.

16. Belhassen S, Zaidi H. A novel fuzzy $\mathrm{C}$-means algorithm for unsupervised heterogeneous tumor quantification in PET. Med Phys 2010;37:1309-24.

17. Brandt ME, Bohan TP, Kramer LA, Fletcher JM. Estimation of CSF, white and gray matter volumes in hydrocephalic children using fuzzy clustering of MR images. Comput Med Imaging Graph 1994; 18:25-34.

18. Carvalho LM, Nassar SM, Azevedo FM, Carvalho HJ, Monteiro LL, Rech CM. A neuro-fuzzy system to support in the diagnostic of epileptic events and non-epileptic events using different fuzzy arithmetical operations. Arq Neuropsiquiatr 2008;66:179-83.

19. Chauvet E, Fokapu O, Hogrel JY, Gamet D, Duchene J.Automatic identification of motor unit action potential trains from electromyographic signals using fuzzy techniques. Med Biol Eng Comput 2003;41:646-53.

20. Ciofolo $C$, Barillot $C$. Atlas-based segmentation of $3 D$ cerebral structures with competitive level sets and fuzzy control. Med Image Anal 2009; 13:456-70.

21. Ciofolo C, Barillot C. Brain segmentation with competitive level sets and fuzzy control. Inf Process Med Imaging 2005; 19:333-44.

22. Cosenza-Andraus ME, Nunes-Cosenza CA, Gomes-Nunes R, FanteziaAndraus C, Alves-Leon SV. Video-electroencephalography prolonged monitoring in patients with ambulatory diagnosis of medically refractory temporal lobe epilepsy: application of fuzzy logic's model. Rev Neurol 2006;43:7-14.
23. Datta S, Sajja BR, He R, Wolinsky JS, Gupta RK, Narayana PA. Segmentation and quantification of black holes in multiple sclerosis. Neuroimage 2006;29:467-74.

24. Dembele D, Kastner P. Fuzzy C-means method for clustering microarray data. Bioinformatics 2003; 19:973-80.

25. Dojat M, HarfA, Touchard D, Laforest M, Lemaire F, Brochard L. Evaluation of a knowledge-based system providing ventilatory management and decision for extubation. Am J Respir Crit Care Med 1996; 153:997- 1004.

26. Ellingson BM, Ulmer JL, Prost RW, Schmit BD. Morphology and morphometry in chronic spinal cord injury assessed using diffusion tensor imaging and fuzzy logic. Conf Proc IEEE Eng Med Biol Soc 2006; I: 1885-8.

27. Emblem KE, Nedregaard B, Hald JK, Nome T, Due-Tonnessen P, Bjornerud A. Automatic glioma characterization from dynamic susceptibility contrast imaging: brain tumor segmentation using knowledge-based fuzzy clustering. J Magn Reson Imaging 2009;30:1-10.

28. Grant P, Naesh O. Fuzzy logic and decision-making in anaesthetics. J R Soc Med 2005;98:7-9.

29. Hanson CW, 3rd, Marshall BE. Artificial intelligence applications in the intensive care unit. Crit Care Med 2001;29:427-35.

30. Hazelzet JA. Can fuzzy logic make things more clear? Crit Care 2009; 13:1 16.

31. Helgason CM. The application of fuzzy logic to the prescription of antithrombotic agents in the elderly. Drugs Aging 2004;21:731-6.

32. Helgason CM, Jobe TH. Causal interactions, fuzzy sets and cerebrovascular 'accident': the limits of evidence-based medicine and the advent of complexitybased medicine. Neuroepidemiology 1999;18:64-74.

33. Helgason CM, Jobe TH. Fuzzy logic and causal reasoning with an ' $n$ ' of I for diagnosis and treatment of the stroke patient. Expert Rev Neurother 2004:4:249-54.

34. Helgason CM, Jobe TH. Fuzzy logic and continuous cellular automata in warfarin dosing of stroke patients. Curr Treat Options Cardiovasc Med 2005;7:211-8.

35. Helgason CM, Malik DS, Cheng SC, Jobe TH, Mordeson JN. Statistical versus fuzzy measures of variable interaction in patients with stroke. Neuroepidemiology 200I;20:77-84.

36. Hu H, Li S,Wang Y, Qi X, Shi Z.The universal fuzzy logical framework of neural circuits and its application in modeling primary visual cortex. Sci China $C$ Life Sci 2008;5I:902-12.

37. Huang SJ, Shieh JS, Fu M, Kao MC. Fuzzy logic control for intracranial pressure via continuous propofol sedation in a neurosurgical intensive care unit. Med Eng Phys 2006;28:639-47.

38. Huang W, Zhang J, Huang D. A simple method to analyze the similarity of biological sequences based on the fuzzy theory. JTheor Biol 20 I0;265:323-8.

39. Jacobs R. Control model of human stance using fuzzy logic. Biol Cybern 1997;77:63-70.

40. Janda M, Bajorat J, Simanski O, Kahler R, Pohl B, Noldge-Schomburg GF, et al. Feedback control of depth of anesthesia during propofol administration: Bispectral index as the controlled variable. Anaesthesist 2010;59:62I-7. Jeyabalan V, Samraj A. Motor imaginary-based brain-machine interface design using programmable logic controllers for the disabled. Comput Met Biomech Biomed Engin 2010 in press.

4I. Jo HG, Park JY, Lee CK,An SK, Yoo SK. Genetic fuzzy classifier for sleep stage identification. Comput Biol Med 2010;40:629-34.

42. Jobe TH, Helgason CM.The fuzzy cube and causal efficacy: Representation of concomitant mechanisms in stroke. Neural Netw 1998; 1 1:549-55.

43. Jobe TH, Helgason CM, Roitberg BZ."Show me the numbers":The application of numbers to medical science. Surg Neurol 200I;56:3-7.

44. Kannan SR, Ramathilagam S, Sathya A, Pandiyarajan R. Effective fuzzy c-means based kernel function in segmenting medical images. Comput Biol Med 2010;40:572-9.

45. Keller T, Bitterlich N, Hilfenhaus S, Bigl H, Loser T, Leonhardt P. Tumour markers in the diagnosis of bronchial carcinoma: New options using fuzzy logic-based tumour marker profiles. J Cancer Res Clin Oncol 1998;124: 565-74.

46. Kocer $\mathrm{S}$. Classification of EMG signals using neuro-fuzzy system and diagnosis of neuromuscular diseases. J Med Syst 2010;34:32I-9.

47. Kouame D, Biard M, Girault JM, Bleuzen A. Adaptive AR and neurofuzzy approaches: Access to cerebral particle signatures. IEEE Trans Inf Technol Biomed 2006; 10:559-66. 
48. Kovacs M, Juranovics J.“Auctoritas” psychiatric expert system shell. Medinfo 1995;8:997.

49. Lan TH, Loh EW,Wu MS, Hu TM, Chou P, LanTY, et al. Performance of a neurofuzzy model in predicting weight changes of chronic schizophrenic patients exposed to antipsychotics. Mol Psychiatry 2008; I 3: I I 29-37.

50. Lee CS, Wang MH. A fuzzy expert system for diabetes decision support application. IEEE Trans Syst Man Cybern B Cybern 2010 in press.

51. Lekkas S, Mikhailov L. Evolving fuzzy medical diagnosis of Pima Indians diabetes and of dermatological diseases. Artif Intell Med 2010;50:1 17-26.

52. Li M,Ye ZQ. Monitoring the depth of anesthesia using a fuzzy neural network based on EEG. Zhongguo Yi Liao Qi Xie Za Zhi 2006;30:253-5.

53. Licata G. Probabilistic and fuzzy logic in clinical diagnosis. Intern Emerg Med 2007;2:100-6.

54. Lin GC,Wang CM,WangWJ, Sun SY.Automated classification of multispectral MR images using unsupervised constrained energy minimization based on fuzzy logic. Magn Reson Imaging 2010;28:721-38.

55. Liu J, Udupa JK, Odhner D, Hackney D, Moonis G.A system for brain tumor volume estimation via MR imaging and fuzzy connectedness. Comput Med Imaging Graph 2005;29:21-34.

56. MA Hatiboglu AA, Ozger M, Iplikcioglu AC, Cosar M,Turgut N.A predictive tool by fuzzy logic for outcome of patients with intracranial aneurysm. Exp Syst Appl 2010;37:1043-9.

57. Magy Seif El-Nasr J. FLAME-Fuzzy logic adaptive model of emotions autonomous agents and multi-agent systems. Auton Agent Multi-Agent Syst 2004;3:219-57.

58. Mahfouf M,Abbod MF, Linkens DA. A survey of fuzzy logic monitoring and control utilisation in medicine. Artif Intell Med 2001;21:27-42.

59. Martin JF. Fuzzy control in anesthesia. J Clin Monit 1994; 10:77-80.

60. Mason DG, Ross JJ, Edwards ND, Linkens DA, Reilly CS. Self-learning fuzzy control with temporal knowledge for atracurium-induced neuromuscular block during surgery. Comput Biomed Res 1999;32: I87-97.

6I. Massaro DW, Cohen MM. Perceiving speech from inverted faces. Percept Psychophys 1996;58:1047-65.

62. Miller DJ, Nelson CA, Oleynikov D. Shortened OR time and decreased patient risk through use of a modular surgical instrument with artificial intelligence. Surg Endosc 2009;23:1099-105.

63. Mohamed SS, Li JM, Salama MM, Freeman GH, Tizhoosh HR, Fenster A, et al. An automated neural-fuzzy approach to malignant tumor localization in 2D ultrasonic images of the prostate.J Digit Imaging 2010 in press.

64. Moonis G, Liu J, Udupa JK, Hackney DB. Estimation of tumor volume with fuzzy-connectedness segmentation of MR images. AJNR Am J Neuroradiol 2002;23:356-63

65. Morris MK, Saez-Rodriguez J, Sorger PK, Lauffenburger DA. Logic-based models for the analysis of cell signaling networks. Biochemistry 2010;49: 3216-24.

66. Mzenda B, Hosseini-Ashrafi M, Gegov A, Brown DJ. A fuzzy convolution model for radiobiologically optimized radiotherapy margins. Phys Med Biol 2010;55:3219-35.

67. Naranjo CA, Bremner KE, Bazoon M, Turksen IB. Using fuzzy logic to predict response to citalopram in alcohol dependence. Clin PharmacolTher 1997;62:209-24

68. Nault ML, Labelle H,Aubin CE, Balazinski M. The use of fuzzy logic to select which curves need to be instrumented and fused in adolescent idiopathic scoliosis: A feasibility study. J Spinal Disord Tech 2007;20:594-603.

69. Nemoto T, Hatzakis GE,Thorpe CW, Olivenstein R, Dial S, Bates JH.Automatic control of pressure support mechanical ventilation using fuzzy logic. Am J Respir Crit Care Med 1999;160:550-6.

70. Nunes CS,Amorim P.A neuro-fuzzy approach for predicting hemodynamic responses during anesthesia. Conf Proc IEEE Eng Med Biol Soc 2008;2008: 58|4-7.

7I. Nunes CS, Mahfouf M, Linkens DA, Peacock JE. Modelling and multivariable control in anaesthesia using neural-fuzzy paradigms: Part I: Classification of depth of anaesthesia and development of a patient model. Artif Intell Med 2005;35:195-206.

72. Obot OU, Uzoka FM. Experimental study of fuzzy-rule based management of tropical diseases: Case of malaria diagnosis. Stud Health Technol Inform 2008; 137:328-39.

73. Ohayon MM. Improving decisionmaking processes with the fuzzy logic approach in the epidemiology of sleep disorders. J Psychosom Res
1999;47:297-3।I.

74. Pagava K, Kiseleva T. New approach to estimate different drugs and/or other medical interventions effectiveness based on fuzzy logic principles. Georgian Med News 2008;5:65-8.

75. Pandey B, Mishra RB. Knowledge and intelligent computing system in medicine. Comput Biol Med 2009;39:215-30.

76. Patriarche J, Erickson B.A review of the automated detection of change in serial imaging studies of the brain. J Digit Imaging 2004; 17:158-74.

77. Pena-Reyes CA. Evolutionary fuzzy modeling human diagnostic decisions. Ann NYAcad Sci 2004; 1020:190-21 I.

78. Phillips WE, 2nd,Velthuizen RP, Phuphanich S, Hall LO, Clarke LP, Silbiger ML. Application of fuzzy c-means segmentation technique for tissue differentiation in MR images of a hemorrhagic glioblastoma multiforme. Magn Reson Imaging 1995; I 3:277-90.

79. Prochazka A.The fuzzy logic of visuomotor control. Can J Physiol Pharmacol 1996;74:456-62.

80. Qing L, Haiteng J, Haiyan L, Gang L, Gaojun T, Zhijian Y. Depression severity evaluation for female patients based on a functional MRI model.J Magn Reson Imaging 2010;31:1067-74.

8I. Ressom H, Reynolds R, Varghese RS. Increasing the efficiency of fuzzy logicbased gene expression data analysis. Physiol Genomics 2003;13:107-I7.

82. Roitberg B. Fuzzy logic in the neurosurgical intensive care unit. Surg Neurol 2006;65:217.

83. Roitberg B. Research news and notes. Surg Neurol 2008;69:439-40.

84. Ross JJ, Mason DG, Linkens DA, Edwards ND. Self-learning fuzzy logic control of neuromuscular block. Br J Anaesth 1997;78:4I2-5.

85. Russell Andrews RM, Papasin R, Guerrero M, DaSilva L. The NASA smart probe for real-time tissue identification: Potential applications in neurosurgery minimally invasive neurosurgery and multidisciplinary Neurotraumatology 2007;1:3-7.

86. Samani A, Holtermann A, Sogaard K, Madeleine P.Active biofeedback changes the spatial distribution of upper trapezius muscle activity during computer work. Eur J Appl Physiol 2010;1 10:415-23.

87. Samani A, Holtermann A, Sogaard K, Madeleine P. Advanced biofeedback from surface electromyography signals using fuzzy system. Med Biol Eng Comput 2010;48:865-73.

88. Samejima H, Ushikubo Y, Mizokami T, Aoki K, Iwabuchi S, Kasai K, et al. New screening system for unruptured cerebral aneurysms-combination of an expert system and DSA examination. Neurol Med Chir (Tokyo) 1990;30:575-81.

89. Saraoglu HM, Sanli S. A fuzzy logic-based decision support system on anesthetic depth control for helping anesthetists in surgeries. J Med Syst 2007;31:5II-9.

90. Schmidt B, Bocklisch SF, Passler M, Czosnyka M, Schwarze JJ, Klingelhofer J. Fuzzy pattern classification of hemodynamic data can be used to determine noninvasive intracranial pressure. Acta Neurochir Suppl 2005;95:345-9.

91. Schneider J, Bitterlich N,Velcovsky HG, Morr H, Katz N, Eigenbrodt E. Fuzzy logic-based tumor-marker profiles improved sensitivity in the diagnosis of lung cancer. Int J Clin Oncol 2002;7:|45-5I.

92. Schneider J, Peltri G, Bitterlich N, Neu K,Velcovsky HG, Morr H, et al. Fuzzy logic-based tumor marker profiles including a new marker tumor M2-PK improved sensitivity to the detection of progression in lung cancer patients. Anticancer Res Am 2003;23:899-906.

93. Seker H, Odetayo MO, Petrovic D, Naguib RN. A fuzzy logic based-method for prognostic decision making in breast and prostate cancers. IEEE Trans Inf Technol Biomed 2003;7: I |4-22.

94. Shamim MS, Enam SA, Qidwai U. Fuzzy Logic in neurosurgery: Predicting poor outcomes after lumbar disk surgery in $50 \mathrm{I}$ consecutive patients. Surg Neurol 2009;72:565-72; discussion 572.

95. Shen S, Szameitat AJ, Sterr A.An improved lesion detection approach based on similarity measurement between fuzzy intensity segmentation and spatial probability maps. Magn Reson Imaging 2010;28:245-54.

96. Shieh JS, Fu M, Huang SJ, Kao MC. Comparison of the applicability of rule-based and self-organizing fuzzy logic controllers for sedation control of intracranial pressure pattern in a neurosurgical intensive care unit. IEEE Trans Biomed Eng 2006;53:1700-5.

97. Simone Hemm FC, Coste J, Vassal F, Nuti C, Derost P, Ouchchane L, et al. Postoperative control in deep brain stimulation of the subthalamic region: the contact membership concept. Int J Comput Assist Radiol Surg 2008;3:69-77. 
98. Torres A, Nieto JJ. Fuzzy logic in medicine and bioinformatics. J Biomed Biotechnol 2006;2006:91908.

99. Torres A, Nieto JJ. The fuzzy polynucleotide space: Basic properties. Bioinformatics 2003; 19:587-92.

100. Ubeyli ED. Fuzzy similarity index for discrimination of EEG signals. Conf Proc IEEE Eng Med Biol Soc 2006; 1:5346-9.

101. Uncu U. Evaluation of pulmonary function tests by using fuzzy logic theory. J Med Syst 2010;34:241-50.

102. Vaidyanathan M, Clarke LP, Hall LO, Heidtman C, Velthuizen R, Gosche K, et al. Monitoring brain tumor response to therapy using MRI segmentation. Magn Reson Imaging 1997; 15:323-34.

103. Velthuizen RP, Clarke LP, Phuphanich S, Hall LO, Bensaid AM, Arrington JA, et al. Unsupervised measurement of brain tumor volume on MR images. J Magn Reson Imaging 1995;5:594-605.

104. Villeger A, Ouchchane L, Lemaire JJ, Boire JY.Assistance to planning in deep brain stimulation: data fusion method for locating anatomical targets in MRI. Conf Proc IEEE Eng Med Biol Soc 2006; I: $144-7$.

105. Vitez TS, Wada R, Macario A. Fuzzy logic: Theory and medical applications. J Cardiothorac Vasc Anesth 1996; 10:800-8.
106. Ye CZ, Yang J, Geng DY, Zhou Y, Chen NY. Fuzzy rules to predict degree of malignancy in brain glioma. Med Biol Eng Comput 2002;40:145-52.

107. Yoder L. Explicit logic circuits predict local properties of the neocortex's physiology and anatomy. PLoS One 2010;5:e9227.

108. Yusuf Alper Kilic AK,Yorganci K, Sayek I.A novel fuzzy-logic inference system for predicting trauma-related mortality: Emphasis on the impact of response to resuscitation. Eur J Trauma Emerg Surg 2010 in press.

109. Zadeh L.The calculus of fuzzy if/then rules. Al Exp 1992;7:22-7.

I I. Zadeh L. Fuzzy sets. Inform Control 1965;8:338-53.

III. Zahlmann G, Kochner B, Ugi I, Schuhmann D, Liesenfeld B, Wegner A, et al. Hybrid fuzzy image processing for situation assessment. IEEE Eng Med Biol Mag 2000; 19:76-83.

1 12. Zhang D, Zhu K. Modeling biological motor control for human locomotion with functional electrical stimulation. Biol Cybern 2007;96:79-97.

1 13. Zhuge $Y$, Udupa JK. Intensity standardization simplifies brain MR image segmentation. Comput Vis Image Underst 2009; I 13:1095-103.

1 14. Zouridakis G, Boutros NN, Jansen BH.A fuzzy clustering approach to study the auditory P50 component in schizophrenia. Psychiatry Res 1997;69:169-8I. 